\title{
RECRIAÇÃO TAYLORISTA: um estudo de caso
}

ROSIVALDO PELLEGRINI

Prof. do Departamento de Ciências Sociais da Universidade Estadual de Londrina

A preocupação deste artigo reside em analisar o discurso de determinada empresa. Seu porta-voz afirma ter descoberto "algo revolucionário" nas relações de trabalho: "A política de méritos". Entende ser "sua empresa" moderna e eficiente. Porém ao analisarmos a obra de F.W.Taylor, (Princípios de Administração Científica), confrontando-a com as relações de trabalho nessa empresa, deixa-nos a tese de que tratar-se-ia de determinada recriação taylorista.

Palavras-Chave: Trabalho; Organização; Taylorismo

\section{APRESENTAÇÃO}

$\mathrm{E}$ ste artigo* procura trabalhar um universo específico: um estudo de caso numa empresa com doutrina organizacional taylorista. Encontraríamos na organização da

empresa determinado caráter tradicional onde o trabalho estaria sendo taylorizado no setor de oficina.

O controle do processo desdobrar-se-ia em dois níveis: $1^{\circ}$ ) $\mathrm{Na}$ informatização do setor de oficina; $2^{\circ}$ ) No discurso ideológico da empresa.

O controle exercido pela empresa através da chamada "Política de Méritos", trata-se na verdade de uma recriação taylorista. Nisso levamos em conta: $\left.1^{\circ}\right)$ O nível de comparação de dois discursos: a obra de Taylor com o discurso da empresa; $2^{\circ}$ ) A semelhança do método da empresa no setor de oficina com o método de Taylor.

Optamos aqui por destacar o discurso do gerente de vendas, introdutor da "Política de Méritos" da empresa, para na teorização comparálo com o discurso de Taylor do século XIX. Esta comparação permite a ilustração empírica sobre a forma de doutrinação na/da empresa através de recriação taylorista.

O discurso de Taylor será aqui analisado dentro de sua própria obra, Princípios de Administração Científica; onde procuramos apreender o discurso taylorista e confrontá-lo com o da empresa. Está embutido neste método (Taylorismo ou "Política de Méritos") maior exploração dos trabalhadores; menor controle destes sobre o trabalho executado; maior parcelamento de suas funções; ampliação do domínio da empresa à revelia dos trabalhadores através da informatização; etc. Reforçamos também a tese da "Política de Méritos" ser recriação taylorista na medida em que o trabalho na oficina conserva seu caráter manual, recriando assim determinada forma de manufatura.

\section{RECRIAÇÃO TAYLORISTA - UM ESTUDO DE CASO (ANALOGIA ENTRE O DISCURSO DO ENTREVISTADO NA EMPRESA E TAYLOR)}

$\mathrm{O}$ entrevistado, gerente de vendas e responsável pela implantação da "Política de Méritos" na empresa estudada, afirma o seguinte:

"O sistema de méritos não foi só criação de uma pessoa. Houve participação nossa e do pessoal de informática. Da turma que participou dessa elaboração (1989) só estou eu. Foi uma equipe. Trabalho em grupo."

Prossegue, agora em tom de deboche, distinguindo o "seu sistema" dos anteriores:

"Sistema convencional de marcação
de tempo? Apontador, essas coisas?
Então como é que funciona? Chega
lá, pega a ordem de serviço e marca 
ali. Aí o apontador vai lá, acha a ficha do cara, vai, põe o relógio e "prim"! Começa! Depois que acaba o tempo: "prim", e vai! Aí no final do dia ou no final do serviço, ele soma todos os tempos e faz o levantamento do aproveitamento, disponibilidade, eficiência. ( $O$ problema aqui é achar a eficiência!).

"Vamos supor que eu sou seu amigo. Você é o apontador e eu sou seu amigo. Eu preciso melhorar meu tempo, pô, quebra o galho! Pô, pega a borracha, apaga ali, $+2-2$ Você acha que alguém vai pegar aqueles cartões e ficar conferindo? Somando uma por uma? Hora por hora, pra ver quantas horas deu? Não faz. Impossível. E não é só isso. O apontador também erra. $O$ que acontece? Prejudica alguém. Agora, $o$ apontador pode ser seu inimigo $e$ diz: eu vou ferrar esse cara!

Não existia confiança no sistema. A maior dificuldade era essa. Então, só foi possivel implantar esse sistema de premiação por méritos a partir do momento que nós informatizamos os controles. Porque daí eu tenho segurança de dizer que é VERDADEIRO “

O discurso de Taylor (1970:43) também caminhava nesse sentido. Isto é, ele acreditava que seu método não era simplesmente uma técnica ardilosa para maior extração de mais valia. Acreditava sim que estava fazendo ciência, portanto buscando a verdade, melhor dizendo: tratava-se de uma ciência positiva, portanto encontrara a verdade nesse método revolucionário. Caberia agora aprimorá-lo.

Entendemos que a empresa estudada também exerça esse papel. Ou seja, aprimora o método de Taylor emoldurando-o com o auxílio da informática, porém possuindo os mesmos valores no que se refere á "natureza do homem" e à noção de ciência.

Taylor realizaria inúmeras experiências antes de aprovar seu método. Método este que basicamente consistiria em aumentar o ritmo de trabalho, diminuindo com técnicas de estudos e movimentos o tempo de cada tarefa, aumentando assim a produção e retirando o controle parcial que ainda o trabalhador detinha sobre o processo de trabalho.

Taylor (1970:49) deixa claro que à gerência é atribuída a função de reunir todos os conhecimentos tradicionais que, no passado, possuíram os trabalhadores, e então classificá-los, tabulá-los, reduzi-los a normas, leis ou fórmulas, "grandemente úteis ao operário para execução do seu trabalho diário".

Taylor (1970:72) narra o seu plano de trabalho com fichas de controle de cada trabalhador, com produção e serviços prestados etapa por etapa:
“ A fim de que todos os homens tivessem ferramentas e instruções para realizar cada novo trabalho, foi necessário organizar um plano minucioso que os orientasse no serviço, em vez do velho sistema de dirigi-los em grandes grupos, subordinados a alguns capatazes. Ao chegar à fábrica, de manhã, o trabalhador tirava de caixa especial, com seu número na parte externa, duas fichas - uma indicava os instrumentos que devia buscar no depósito e o lugar em que devia começar a trabalhar e a outra continha um resumo de sua produção no dia anterior, isto é, uma relação do serviço que fizera e quanto ganhara naquele dia, etc. Quando recebiam ficha branca tudo ia bem, mas a ficha amarela indicava que deviam melhorar, senão seriam substituidos. “

Na empresa estudada não existem fichas feitas manualmente à espera do mecânico, mas sim a ordem de serviço que o próprio trabalhador retira da impressora ligada ao computador. Nela também constará o serviço específico a ser executado e tempo estimado para realizá-lo. O mecânico passará o crachá no controle óptico e imediatamente dispara o tempo. Já o resumo de sua produção não será dado no final do dia como nos tempos de Taylor, mas a cada serviço executado. Porém, entendemos 
que a finalidade seja a mesma, assim como os meios, com a ressalva de que auxiliados pela informática. Taylor (1970:73) afirmara que:

\section{"Deixando de lidar com homens, em grandes equipes ou grupos, e passando a considerar cada trabalhador individualmente, entregamos o trabalhador que falha em sua tarefa a instrutor competente para lhe indicar o melhor modo de executar o serviço e para guiá-lo, ajudá-lo e encorajá-lo, bem como estudar suas possibilidades como trabalhador ".}

O "instrutor competente de Taylor" não seria o "chefe de serviços da empresa estudada" ? Isto porque cada setor da oficina da empresa estudada tem o seu chefe. E, segundo o entrevistado, cabe ao chefe de serviços fiscalizar o andamento do processo de trabalho. Eis seu relato acerca desse ponto:

" Eu tenho chefes. A cada serviço finalizado, o mecânico tem a obrigação de entregar a sub/ordem pro chefe. O chefe vai lá, faz o controle final de qualidade e passa a sub/ordem na pistola óptica. $\mathrm{Na}$ hora em que o chefe passar isso, já sai a eficiência e o aproveitamento naquele serviço".

Adentremos no papel exercido pelo chefe de serviços na empresa estudada. Este é orientado de que torna-se normal uma eficiência de $80 \%$ a $120 \%$. Significa que o mecânico pode variar $20 \%$ para mais e $20 \%$ para menos. Se eu tenho 1 hora pra cada tarefa, vai dar $100 \%$. Se eu gastei 80 centésimos $(0,80)$ vai dar $120 \%$. Se eu gastei 120 centésimos de hora, vai dar $80 \%$ de eficiência. Essa variação é tolerada dentro da empresa.

Aprofundemos o entendimento do funcionamento da "Política de Méritos" : se der a mais que essa faixa ( $80 \%$ a $120 \%$ ) ou a menos, o chefe já checa na hora o que aconteceu. Claro, a preocupação predominante é com o tempo na execução do serviço. Vale dizer, toda a "Política de Méritos" é centrada nessa preocupação. Menor tempo possível, com qualidade no serviço. Portanto, se o mecânico consegue terminar um serviço em menos tempo que o tempo padrão estimado, o chefe é acionado. Cabe a ele verificar por que o mecânico conseguiu terminar em menos tempo que o tempo padronizado, claro, computando os méritos para o mecânico, porém verificando detalhadamente todo o serviço e questionando o mecânico sobre o tempo obtido. De 3 em 3 meses os tempos são novamente estudados para serem diminuídos, prevalecendo assim um novo tempo padrão. No caso daqueles mecânicos que ultrapassam o tempo padrão, ou seja, levam mais tempo para terminarem suas tarefas, serão imediatamente observados pelos chefes de setores através do comunicado do responsável pelo planejamento (o planejador observa através da tela do computador, controlando tempos, movimentos e serviços de cada um, e comunicando os chefes de setor). Sendo assim, os mecânicos perdem os méritos quando o tempo "estoura" e ficam com os empregos ameaçados caso persistam os "estouros" de tempo.

Perguntamos: Com Taylor era muito diferente? Eis sua afirmação sobre esse tema: (1970:72)

“O papel amarelo indicava que o
trabalhador não conseguira efetuar
a tarefa completa no dia anterior e
informava-o de não ter ganho $\$ 1,85$
dólares nesse dia. E como todos
sabiam que somente era permitida a
permanência, nesta equipe, de bons
operários, isso correspondia á
advertência de que procurassem
ganhar salário completo no dia
seguinte. Quando recebiam ficha
branca tudo ia bem, mas a ficha
amarela indicava que deviam
melhorar, senão seriam substituídos
“

A empresa estudada trocou o papel amarelo e a ficha branca de Taylor pelo computador. $\mathrm{O}$ controle de todo o processo de trabalho no setor de oficina é feito pelos recursos da informatização. Não seria o caso de perguntarmos: sem o computador e a pistola óptica, não estaríamos no taylorismo puro do século XIX ?

Vejamos agora a natureza do serviço dos que Taylor (1970:113) denominou de supervisores:

“A natureza humana é de tal sorte
que muitos operários, abandonados
a si mesmos, dispensam pouca
atenção ás instruções escritas.
Assim, torna-se necessário designar
instrutores, chamados chefes
funcionais, para observar se os
trabalhadores entendem e aplicam
as instruções. (...) Sendo cada um
escolhido por seus conhecimentose

"A natureza humana é de tal sorte que muitos operários, abandonados a si mesmos, dispensam pouca atenção ás instruções escritas. Assim, torna-se necessário designar instrutores, chamados chefes funcionais, para observar se os aplicam escolhido por seus conhecimentos $e$ 


\begin{abstract}
habilidade pessoal na especialidade, é capaz, não somente de dizer o que deve fazer o trabalhador, mas, no caso de necessidade, também executar o serviço na frente do operário, de modo que lhe exemplifique o melhor método de realizar o trabalho".
\end{abstract}

Os chefes de setores da empresa estudada são mecânicos altamente habilitados, segundo nos informa o responsável pela "Política de Méritos". Ele mesmo, o gerente que concedeu a entrevista, teria testado um caminhão e saiu-se melhor que a maioria dos motoristas de estrada. Sendo assim, o entendimento que temos é que os chefes não só dariam ordens e supervisionariam, como também seriam um exemplo a ser seguido, posto que sabem fazer melhor aquele serviço e o fazem em menos tempo. Como não identificamos "operário padrão" nessa empresa, suspeitamos que ele é substituído no discurso ideológico pelo "chefe de setor padrão"

Retomemos o pensamento de Taylor (1970:82). Este acreditava em "natureza humana" . E pelo exposto a "natureza humana" necessitaria sempre de comando. Comando exposto de cima para baixo posto que questionamentos ou mesmo uma democracia representativa não funcionariam com seu método.

“Tal aceleração do trabalho só poderá ser obtida por meio da padronização obrigatória dos métodos, adoção obrigatória dos melhores instrumentos e condições de trabalho e cooperação obrigatórias. E esta atribuição de impor padrões e forças a cooperação compete exclusivamente à gerência “.

Pelo que constatamos na pesquisa empírica, a "Política de Méritos" da empresa estudada também foi introduzida de forma autoritária. Não foram consultados os mecânicos e tampouco os funcionários de uma maneira geral. $\mathrm{O}$ proprietário da empresa exigia maior produtividade visto não haver concorrência à altura na região, como também a margem de lucro não aumentava na proporção exigida. Tal informação nos foi dada pelo próprio introdutor da "Política de Méritos", entendendo o procedimento da empresa como "natural" e "necessário".

Em 1989 a alta cúpula da empresa convocou reuniões com diretores e gerentes da empresa. Dessas reuniões surgiu a idéia de escolherem uma equipe do setor de informática. Essa equipe teve a missão de elaborar um método que aumentasse a produtividade e ao mesmo tempo arregimentasse mais clientes. Surgiria desses estudos, segundo o gerente entrevistado, a "Política de Méritos". O próprio gerente, na época, trabalhava no setor de informática, posteriormente passando a ser gerente geral de vendas.

Portanto, o setor de informática da empresa estudada foi o criador dessa política de estudos e movimentos. E no que entendemos, procurou uma coesão entre informática e método taylorista, que a propósito negam. Afirmam ter descoberto algo extraordinário, inédito no Brasil e no mundo, cria da própria casa, que seria o que denominam de "Política de Méritos".

Vejamos a afirmação do entrevistado, introdutor desse método na empresa estudada:

" $E$ muito bom esse sistema. E foi uma iniciativa nossa, totalmente isolada, pela nossa necessidade. Desenvolvida por nós e feita por nós. Não foi feita para comercializar nem nada. Mas despertou alguns interesses. Só que é uma coisa dificil, porque o pessoal ainda tem medo. Tem muito receio de informática. Esse sistema foi desenvolvido aqui dentro. Pelo que eu saiba, só nós temos isso até hoje. Tivemos muitas visitas. Concessionárias da nossa marca, de outras marcas, até visitas de um grupo sueco. Suécia. Responsável pela informatização do mundo. A Scania nos visitou. E estão dispostos a criar esse sistema para o mundo inteiro "

Pelo exposto até aqui nos parece que esse sistema não é tão "inovador" assim, posto que já existia no século XIX.Em 1883, Taylor já realizava experiências com o estudo de tempos e movimentos visando aumentar produção e produtividade:

"Thompson, engenheiro civil, em 1896 começou a estudar o tempo das diversas tarefas da fábrica. Cronometrou dezenas de funções, 
criou métodos próprios de colher dados, folhas de registro $e$ dispositivos para manter o relógio, sem ser visto pelo operário. Estes processos mereceram de Taylor, que fazia a medida do tempo desde 1883, quando se tornou chefe da oficina mecânica na Midvale Steel Co., esta referência: "são os melhores atualmente em uso". (Taylor, 1970:85)

Taylor (1970:73) referia-se ao seu método como "administração científica" e enumera 4 itens que o caracterizariam:

“Tal organização consiste, no caso, em encarregar: $1^{\circ}$ ) Um grupo de homens de desenvolver a ciência do trabalho, mediante o estudo dos tempos, como foi descrito; $2^{\circ}$ ) Outro grupo mais hábil de auxiliar e orientar, como instrutores, os operários no serviço; $3^{\circ}$ ) Outro grupo de armazenar as ferramentas e guardar todo o material em perfeita ordem; $4^{\circ}$ ) Outro enfim, de planejar o trabalho, com antecedência, a fim de mobilizar os homens sem perder tempo e de determinar a sua remuneração diária, etc. “.

Prosseguindo com as semelhanças: $\mathrm{O}$ item $1^{\circ}$ citado por Taylor seria desempenhado pelo pessoal da informática na empresa estudada. No $2^{\circ}$ item, na função de auxiliar e orientar como instrutores, teríamos os chefes de oficina da empresa estudada. No $3^{\circ}$ item encontraríamos uma diferença: no método de Taylor haveria um grupo específico para só armazenar as ferramentas, já na empresa estudada os próprios mecânicos acumulam esse serviço. No $4^{\circ}$ item, Taylor fala de um grupo para planejar o trabalho com antecedência para evitar perda de tempo, remuneração diária, etc. $\mathrm{Na}$ empresa estudada tal serviço coube ao entrevistado. Ele organiza as tarefas, divisões de etapas etc. , entrega ao planejador de serviços que coloca todo o esquema no computador. Cabe então ao planejador de serviços operar o controlador fiscalizando todas as tarefas nos mínimos detalhes.

Desaparece assim a figura do apontador, aquele que fiscalizava diretamente as tarefas. O computador realiza agora esse serviço. Evidentemente com melhor desempenho posto que não falta ao trabalho, não acarreta encargos sociais e tampouco representa alguma ameaça de greve.

\section{NOTAS}

*Este artigo corresponde a um tópico referente ao capítulo III da nossa dissertação de mestrado em sociologia, defendida em de abril de 1996, denominada: "Doutrina Organizacional na Empresa: Informatização, 'Política de Méritos' e Taylorismo".

\section{REFERÊNCIA BIBLIOGRÁFICA}

TAYLOR, Frederick Winslow. Princípios de administração científica. 7.ed. São Paulo, Atlas, 1970. 